\title{
IMPLEMENTASI PROGRAM KAWASAN RUMAH PANGAN LESTARI DI KOTA SEMARANG: POTENSI EKONOMI YANG PERLU DITUMBUHKAN
}

\section{IMPLEMENTATION OF HOMEGARDEN PROGRAM (KRPL) IN SEMARANC CITY: THE ECONOMIC POTENTIAL THAT NEEDS TO BE GROWED}

\author{
Erma Kusumaningsih', Wido Prananing Tyas ${ }^{2}$ \\ 'Badan Ketahanan Pangan; Gedung E Lantai VI Kementerian Pertanian, Jl. Harsono RM No. 3 Jakarta Selatan 12550; \\ ermakusumaningsih@pertanian.go.id \\ 2Departemen Perencanaan Wilayah dan Kota Universitas Diponegoro; Gedung A Lantai III Jurusan Perencanaan Wilayah dan Kota, \\ Kampus Undip Tembalang, Semarang 50275; email penulis w.p.tyas@pwk.undip.ac.id
}

\section{Info Artikel:}

\begin{abstract}
ABSTRAK:
Penelitian yang mengambil lokasi di Kota Semarang ini dimaksudkan untuk mengetahui sejauh mana implementasi program Kawasan Rumah Pangan Lestari (KRPL) di Kota Semarang, dengan fokus untuk melihat karakteristik pelaksanaan program dan menganalisis sejauh mana kontribusi program bagi perekonomian keluarga penerima manfaat program.

Penelitian ini menggunakan metode analisis campuran yang mengelaborasikan analisis kuantitatif dan kualitatif. Analisis kuantitatif dilakukan melalui metode survey dengan menyebarkan kuesioner terhadap seluruh anggota kelompok penerima manfaat program KRPL bersumber dari dana APBN 2018 yang berjumlah 120 orang. Analisis kualitatif digunakan untuk memperkuat analisis kuantitatif, melalui metode wawancara mendalam terhadap aparat Dinas Ketahanan Pangan Kota Semarang dan pendamping kelompok. Berdasarkan hasil penelitian, karakteristik kelompok penerima manfaat program KRPL sebagian besar adalah ibu rumah tangga usia produktif dengan jenjang pendidikan dasar dan menengah. Implementasi program KRPL memiliki potensi yang perlu ditumbuhkan untuk meningkatkan manfaat ekonomi program. Walaupun saat ini, program KRPL masih sebatas untuk konsumsi sendiri dan berkontribusi mengurangi pengeluaran domestik untuk pangan, namun jika digarap dengan serius dan berkelanjutan dengan skala yang lebih luas, progam ini dapat menjadi alternatif untuk meningkatkan kesejahteraan.
\end{abstract}

Kata Kunci : implementasi program; KRPL; Semarang

\begin{abstract}
This study is intended to determine the extent of the implementation of the Kawasan Rumah Pangan Lestari (KRPL) program in Semarang city, with a focus on analyzing the characteristics of its implementation and analyzing the program's contribution to the economies of beneficiary families. This study uses a mixed method that elaborates quantitative and qualitative analysis. Quantitative analysis was carried out through a survey method by distributing questionnaires to all members of the household beneficiaries in 2018, totaling 120 people. Qualitative analysis was used to strengthen quantitative analysis, through in-depth interviews with Semarang Food Security Department officials and companion group of beneficiaries. The results showed that the characteristics of the KRPL program beneficiaries were mostly productive age housewives with primary and secondary education. The implementation of the KRPL program has the potential to grow economic benefits. Even though at present, the KRPL program is limited to self-consumption and contributes to reducing domestic expenditure on food, but if taken seriously and sustainably on a broader scale, this program can be an alternative to improve welfare and reduce urban poverty
\end{abstract}

Kata Kunci : implementation program; homegarden; KRPL; Semarang 
Kusumaningsih, Tyas/ Jurnal Pembangunan Wilayah dan Kota, Vol.15, No.3, 2019

Doi: https://doi.org/10.14710/pwk.v15i3.23061

\section{PENDAHULUAN}

Pemenuhan kebutuhan pangan penduduk menjadi tantangan dan bagian yang tidak terpisahkan dalam pembangunan karena pangan merupakan kebutuhan dasar manusia, sehingga upaya pemenuhannya juga menjadi titik kritis pembangunan. Kekhawatiran mengenai kondisi ketahanan pangan telah terjadi di berbagai belahan dunia, sehingga dikembangkan pendekatan baru yang mengintegrasikan perencanaan kota dengan sistem pangan perkotaan. Salah satu negara yang mencoba menerapkannya adalah Amerika Serikat yang mengintegrasikan antara konsep kota pintar dengan konsep sistem pangan perkotaan, khususnya melalui teknologi pertanian vertikal (Maye, 2018). Sementara itu beberapa negara di Afrika dan Amerika Latin lebih mengembangkan pertanian perkotaan sebagai upaya untuk mewujudkan ketahanan pangan (Badami \& Ramankutty, 2015). Pada pertanian perkotaan, diharapkan pemenuhan pangan tidak hanya bertumpu pada ketersediaan lahan, melainkan dapat memanfaatkan lahan marjinal, lahan pekarangan, mengaplikasikan inovasi teknologi dan melibatkan pemberdayaan masyarakat (Nagoda and Nightingale, 2017; Maye, 2018; Zhang et al., 2018).

Kekhawatiran akan ketahanan pangan juga terjadi di Indonesia, pembangunan wilayah dan pesatnya urbanisasi seringkali diikuti dengan perluasan kawasan perkotaan dan berkurangnya lahan pertanian sehingga mengancam ketahanan pangan (He et al., 2017). Berdasarkan data, penduduk perkotaan di Indonesia pada tahun 2015 telah mencapai 53,3 persen meningkat dari tahun 2010 yang masih berkisar 49,8 persen, dan diproyeksikan akan terus mengalami peningkatan hingga menjadi 66,6 persen pada tahun 2035 (www.bps.go.id). Sementara itu berbanding terbalik dengan tingkat urbanisasi, ketersediaan lahan pertanian mengalami kecenderungan menurun. Kecenderungan laju konversi lahan sawah nasional sebesar 96.512 ha/th, dengan demikian lahan sawah yang ada sekarang seluas 8,1 juta ha diperkirakan akan menciut menjadi hanya sekitar 5,1 juta ha pada tahun 2045 (Mulyani et al., 2015).

Sebagai upaya antisipasi, pemerintah telah memiliki serangkaian upaya mensinergikan kebijakan kebijakan antara Pemerintah Pusat dan Pemerintah Kota, termasuk mengintegrasikannya dengan kebijakan perencanaan pembangunan wilayah. Dalam hal ini Pemerintah Kota Semarang melalui Perda Kota Semarang Nomor 6 Tahun 2016 tentang Rencana Pembangunan Jangka Menengah Kota Semarang Tahun 2016-2021 yang telah diperbarui menjadi Perda Nomor 11 Tahun 2017 telah menetapkan program ketahanan pangan sebagai salah satu program prioritas di lingkungan Kota Semarang. Program ini merupakan salah satu wujud komitmen Pemerintah Kota Semarang untuk mewujudkan ketahanan pangan di Kota Semarang, yang dalam pelaksanaannya bersinergi dengan program KRPL dari Pemerintah Pusat sehingga dapat mengedukasi dan meningkatkan kapasitas masyarakat dalam mengoptimalkan pemanfaatan pekarangan. Oleh karenanya, penelitian ini dimaksudkan untuk mengetahui implementasi program KRPL di Kota Semarang, dengan fokus untuk melihat karakteristik pelaksanaan program dan menganalisis kontribusi program terhadap perekonomian keluarga penerima manfaat program.

Program KRPL identik dengan program sejenis yang disebut dengan program homegarden. Beberapa negara yang telah mempraktekkan program ini diantaranya terdistribusi di bagian Afrika Timur dan Barat, Asia Selatan dan Tenggara, Kepulauan Pasifik dan Meso Amerika sebagai fenomena tropis (Mohri et al., 2013). Hampir sama dengan karakteristik program KRPL, konsep homegarden dicirikan dengan pertanian yang diusahakan oleh rumah tangga dengan tenaga kerja berasal dari anggota keluarga (umumnya wanita, lanjut usia, atau anak-anak), bersifat paruh waktu berlokasi berdekatan dengan tempat tinggal, menggunakan teknologi sederhana, biaya produksi relatif rendah, diusahakan di kawasan perkotaan maupun pedesaan, hasil produksi biasanya untuk konsumsi keluarga dan frekuensi panen bisa dilakukan harian (Niñez, 1987).

Secara umum keberhasilan homegarden banyak dirasakan di beberapa negara yang mengusahakannya. Di Bangladesh misalnya, Pemerintah dikatakan mampu meningkatkan ketahanan pangan dan mengurangi malnutrisi sekaligus mengurangi kemiskinan di kawasan pedesaan Bangladesh (Ferdous et al., 2016). Tidak hanya di Bangladesh, program serupa di negara Jepang dan Uganda juga berkontribusi terhadap ketahanan pangan dan gizi (Kamiyama et al., 2016; Whitney et al., 2017). Program ini 
secara nyata juga memberikan manfaat bagi ekosistem dan lingkungan, yaitu bermanfaat untuk memperkaya biodiversity, meningkatkan stok karbon dan meningkatkan kualitas lingkungan yang telah dilakukan beberapa penelitian di beberapa negara (Kumar, 2011; Mohri et al., 2013; Caballero-Serrano et al., 2016).

Beberapa penelitian mengenai KRPL telah dilakukan dengan lokasi dan fokus yang berbeda. Berdasarkan penelitian sebelumnya, peneliti lebih banyak mengkaji pelaksanaan program dari aspek teknis pertanian dan dampaknya terhadap ketahanan pangan dan gizi masyarakat (Purwantini, Saptana and Suharyono, 2012). Dalam penelitian lain juga dikaji faktor-faktor yang mempengaruhi performa pelaksanaan KRPL (Sirnawati, Yulianti and Ulpah, 2015). Sementara itu, Harnisah, et al (2016) mengukur kinerja model KRPL dari aspek teknis, sosial dan ekonomi pada kelompok tani model. Dalam tulisan lain kegiatan pertanian di pekarangan dikatakan dapat menjadi sumber tambahan penghasilan dan kesempatan kerja bagi masyarakat sehingga dapat menjadi penyangga kestabilan ekonomi di dalam keadaaan kritis dan berkaitan langsung dengan upaya penanggulangan kemiskinan (poverty alleviation) serta lingkungan lestari (Listya et al., 2014).

Berbeda dengan penelitian sebelumnya, penelitian ini dilakukan melalui metode survei kepada seluruh anggota kelompok penerima manfaat program di Kota Semarang pada tahun 2018. Hal ini dilakukan untuk mengetahui karakteristik pelaksanaan program di Kota Semarang, termasuk sebaran dan variasinya. Penelitian ini menggunakan data yang bersumber dari persepsi responden mengenai implementasi program KRPL dengan didukung hasil wawancara kepada beberapa aktor kunci (aparat Dinas Ketahanan Pangan dan pendamping kelompok penerima manfaat program) yang dinilai mengetahui detail pelaksanaan program dalam rangka memperkuat argumentasi.

\section{DATA DAN METODE}

\subsection{Teknik Pengumpulan Data}

Berdasarkan sumbernya, teknik pengumpulan data terbagi menjadi dua macam yaitu pengumpulan data primer dan pengumpulan data sekunder. Sumber data primer adalah sumber data yang langsung memberikan data kepada pengumpul data, sementara sumber data sekunder adalah sumber data yang tidak langsung memberikan data kepada pengumpul data (Sugiyono, 2013). Teknik pengumplan data primer dalam penelitian ini menggunakan kuesioner dan wawancara dengan berpedoman pada daftar pertanyaan. Responden kuesioner adalah anggota kelompok sasaran penerima manfaat program KRPL tahun 2018 di lokasi penelitian seperti terlihat pada Gambar 1 dengan metode sensus yang tertuang di Tabel 1 di bawah ini:

Tabel 1. Kelompok Penerima Manfaat Program KRPL

\begin{tabular}{cllll}
\hline $\begin{array}{c}\text { No. } \\
\text { Kelompok Penerima Manfaat 2018 }\end{array}$ & Desa/ Kelurahan & Nama Kelompok & Jumlah Anggota \\
\hline 1 & Mijen & Kedungpane & Asri 52 & 30 \\
2 & Tugu & Tugurejo & Sumber Hasil & 30 \\
3 & Tembalang & Tandang & Tlumpak Asri & 30 \\
4 & Banyumanik & Gedawang & Mugi Rahayu & 30 \\
& Jumlah & & & 180 \\
\hline
\end{tabular}

Sumber: Dinas Ketahanan Pangan, 2018

\subsection{Metode}

Secara garis besar penelitian ini menggunakan metode campuran yang mengkombinasikan analisis kuantatif dan kualitatif. Analisis kuantitatif diperoleh dengan mengolah hasil kuesioner dengan metode statistik deskriptif guna menggambarkan karakteristik dan preferensi kelompok penerima manfaat mengenai variabel yang ditentukan. Kuesioner disebarkan dengan metode survei dengan responden seluruh 
anggota kelompok sasaran penerima manfaat program KRPL tahun 2018 yang berjumlah 120 orang. Form kuesioner disusun dengan menyertakan pertanyaan-pertanyaan untuk mengetahui karateristik responden dan pendapatnya mengenai pengalaman dalam melaksanakan program KRPL, manfaat apa yang mereka peroleh dari melaksanakan program KRPL, khususnya dilihat dari variabel aspek perekonomian keluarga.

Sementara analisis kualitatif dilakukan untuk mendukung analisis kuantitatif guna mengetahui lebih detail mengenai pelaksanaan program di lapangan dan kendala yang dihadapi. Analisis kualitatif dilakukan bersumber dari data wawancara yang dilakukan terhadap informan kunci yang dianggap telah memahami implementasi program KRPL di Kota Semarang untuk memperoleh informasi yang lebih mendalam. Berdasarkan hal tersebut, maka yang menjadi informan kunci adalah aparat Dinas Ketahanan Pangan Kota Semarang yang menangani program KRPL yang diwakili oleh Kasie Konsumsi Pangan Dinas Ketahanan Pangan Kota Semarang dan pendamping kelompok sebanyak dua orang.

Penulis menggunakan strategi penelitian konkuren, dimana data kuantitatif dan data kualitatif dikumpulkan pada tahapan yang sama untuk selanjutnya diintegrasikan hasil analisisnya untuk menghasilkan kesimpulan hasil penelitian secara menyeluruh (Creswell, 2009).
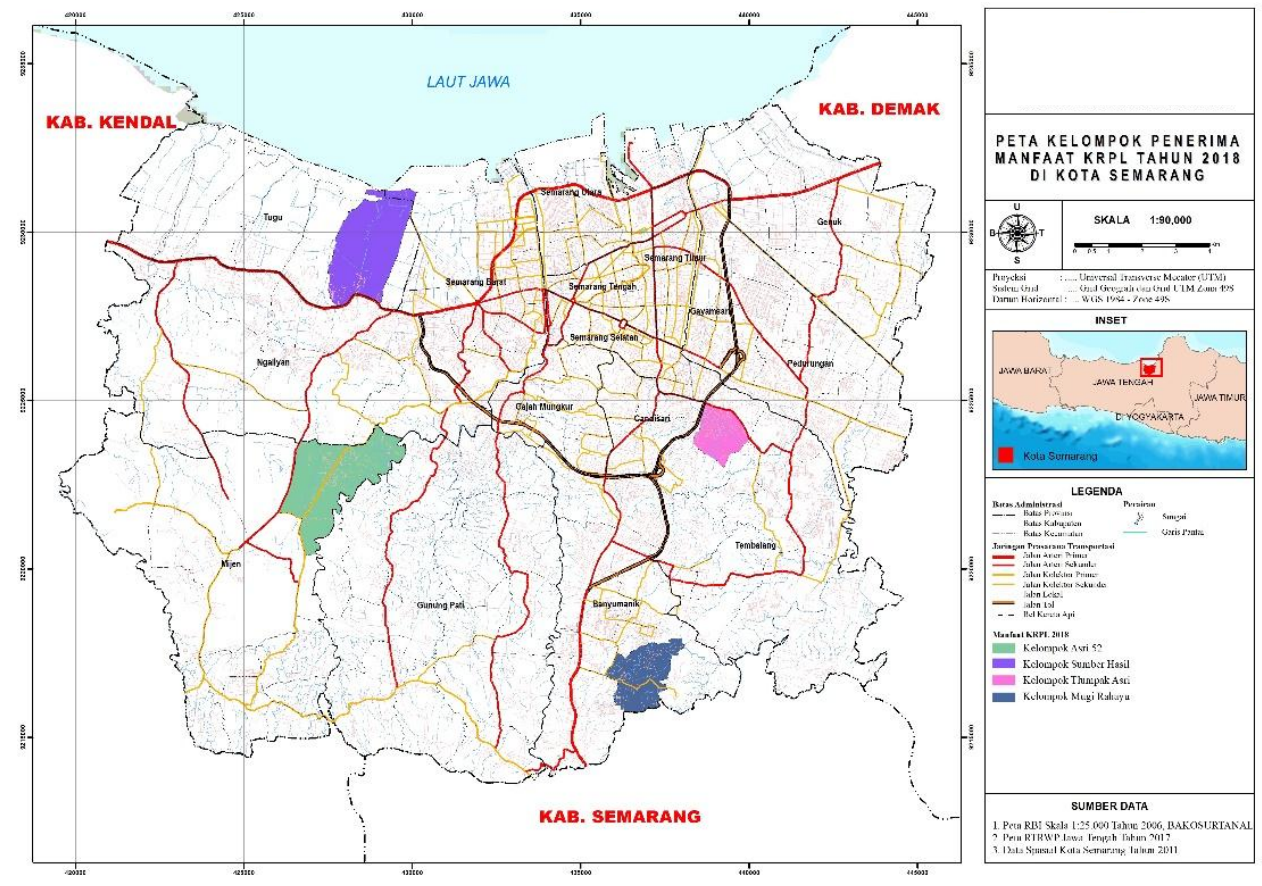

Sumber: Hasil Analisis, 2019

Gambar 1. Peta Lokasi Penelitian

\section{HASIL DAN PEMBAHASAN}

\subsection{Karakteristik Pelaksanaan Program KRPL di Kota Semarang}

Kota Semarang menjadi salah satu kota di Jawa Tengah yang melaksanakan program KRPL. Seperti halnya kota besar lainnya, sebagai ibukota provinsi Jawa Tengah, Kota Semarang dihadapkan pada kompetisi pemanfaatan lahan untuk memenuhi fungsi-fungsi perkotaan. Oleh karena itu, dalam pelaksanaannya KRPL di Kota Semarang memanfaatkan lahan pekarangan di sekitar rumah, baik memanfaatkan pola pertanian konvensional maupun sudah mulai menggunakan teknologi budidaya, seperti vertikultur maupun menggunakan media tanam selain tanah. 
Hasil penelitian yang dilakukan terhadap kelompok penerima manfaat program KRPL Tahun 2018 sebanyak empat kelompok dengan total 120 anggota menggambarkan pelaksanaan program KRPL di Kota Semarang. Karateristik pelaksanaan program KRPL di Kota Semarang diperoleh berdasarkan beberapa fokus pengamatan seperti pada Tabel 1, diantaranya terhadap kelembagaan dan struktur organisasi, pengorganisasi kegiatan, ketersediaan lahan kelompok untuk kebun bibit dan demplot, pengelolaan dan pemanfaatan demplot, pengelolaan dan pemanfaatan kebun bibit, pemanfaatan pekarangan dan kegiatan pendampingan.

Tabel 1. Karakteristik Pelaksanaan Program KRPL di Kota Semarang Tahun 2018 (Hasil Analisis, 2019)

\begin{tabular}{|c|c|c|c|c|c|c|}
\hline Karakteristik & $\begin{array}{c}\text { KWT } \\
\text { Tlumpak } \\
\text { Asri } \\
\end{array}$ & $\begin{array}{c}\text { KWT } \\
\text { Mugi } \\
\text { Rahayu }\end{array}$ & $\begin{array}{c}\text { KWT } \\
\text { Sumber } \\
\text { Hasil }\end{array}$ & $\begin{array}{c}\text { KWT } \\
\text { Asri } \\
52 \\
\end{array}$ & $\mathrm{Jml}$ & $\%$ \\
\hline \multicolumn{7}{|l|}{ Kelembagaan dan struktur organisasi } \\
\hline - punya kelembagaan dan struktur organisasi sah & 30 & 30 & 30 & 30 & 120 & 100 \\
\hline \multicolumn{7}{|l|}{ Pengorganisasian kegiatan } \\
\hline - pengorganisasian kegiatan berjalan & 25 & 30 & 30 & 30 & 115 & 96 \\
\hline - ada pengorganisasian namun tidak berjalan & 5 & - & - & - & 5 & 4 \\
\hline \multicolumn{7}{|l|}{ Ketersediaan lahan kebun bibit dan demplot } \\
\hline - tersedia & 30 & 30 & 30 & 30 & 120 & 100 \\
\hline \multicolumn{7}{|l|}{ Pengelolaan demplot } \\
\hline - dikelola dan dimanfaatkan & 30 & 30 & 30 & 30 & 120 & 100 \\
\hline - tidak dikelola dan dimanfaatkan & - & - & - & - & - & - \\
\hline \multicolumn{7}{|l|}{ Pemanfaatan kebun bibit } \\
\hline - dimanfaatkan anggota kelompok & 8 & - & 9 & - & 17 & 14 \\
\hline - dimanfaatkan masyarakat & 22 & 30 & 21 & 30 & 103 & 86 \\
\hline -tidak dikelola dan dimanfaatkan & - & - & - & - & - & - \\
\hline \multicolumn{7}{|l|}{ Pemanfaatan pekarangan untuk KRPL } \\
\hline - seluruh pekarangan & - & - & 20 & - & 20 & 17 \\
\hline - sebagian besar & 5 & 20 & 3 & 5 & 33 & 28 \\
\hline - sebagian kecil & 25 & 10 & 7 & 25 & 67 & 56 \\
\hline - tidak punya & & & & & & \\
\hline
\end{tabular}

Sumber: Hasil Analisis, 2019

Program KRPL dilaksanakan dengan kelompok sasaran berupa kelompok wanita atau dasawisma atau kelompok masyarakat yang beranggotakan rumah tangga yang berdomisili berdekatan dalam satu desa atau kelurahan. Kelompok penerima manfaat program KRPL beranggotakan ibu rumah tangga, dengan alasan ibu memegang peran penting dalam pengambilan keputusan mengenai kebutuhan rumah tangga dan mengendalikan pengeluaran rumah tangga untuk pangan, non pangan dan tabungan (Akter et al., 2017).

Yang dimaksud karakteristik dalam penelitian ini adalah ciri yang secara alamiah melekat pada kelompok penerima manfaat program KRPL meliputi usia responden, tingkat pendidikan, status pekerjaan dan luas pekarangan. Karakteristik ini menggambarkan kondisi kelompok penerima manfaat program, dengan kondisi dan sebaran disajikan pada Gambar 2.

Hasil penelitian menggambarkan bahwa seluruh kelompok penerima manfaat program KRPL mampu menyediakan lahan untuk kebun bibit dan demonstration plot (demplot) kelompok. Pengelolaan dan pemanfaatan demplot dan kebun bibit masih berjalan baik pada seluruh kelompok penerima manfaat program KRPL Tahun 2018. Demplot dimanfaatkan sebagai kebun oleh kelompok untuk praktek dan belajar bersama anggota kelompok. Pengelolaan dilakukan bersama-sama dengan ada mekanisme piket anggota kelompok untuk merawat tanaman dan kerja bakti yang biasa dilakukan seminggu sekali. Kebun bibit dapat dimanfaatkan untuk mengisi tanaman di demplot kelompok dan dapat diakses oleh anggota kelompok 
Kusumaningsih, Tyas/ Jurnal Pembangunan Wilayah dan Kota, Vol.15, No.3, 2019

Doi: https://doi.org/10.14710/pwk.v15i3.23061

untuk dimanfaatkan di pekarangan rumah masing-masing. Kondisi demplot dan kebun bibit kelompok seperti nampak pada Gambar 3.

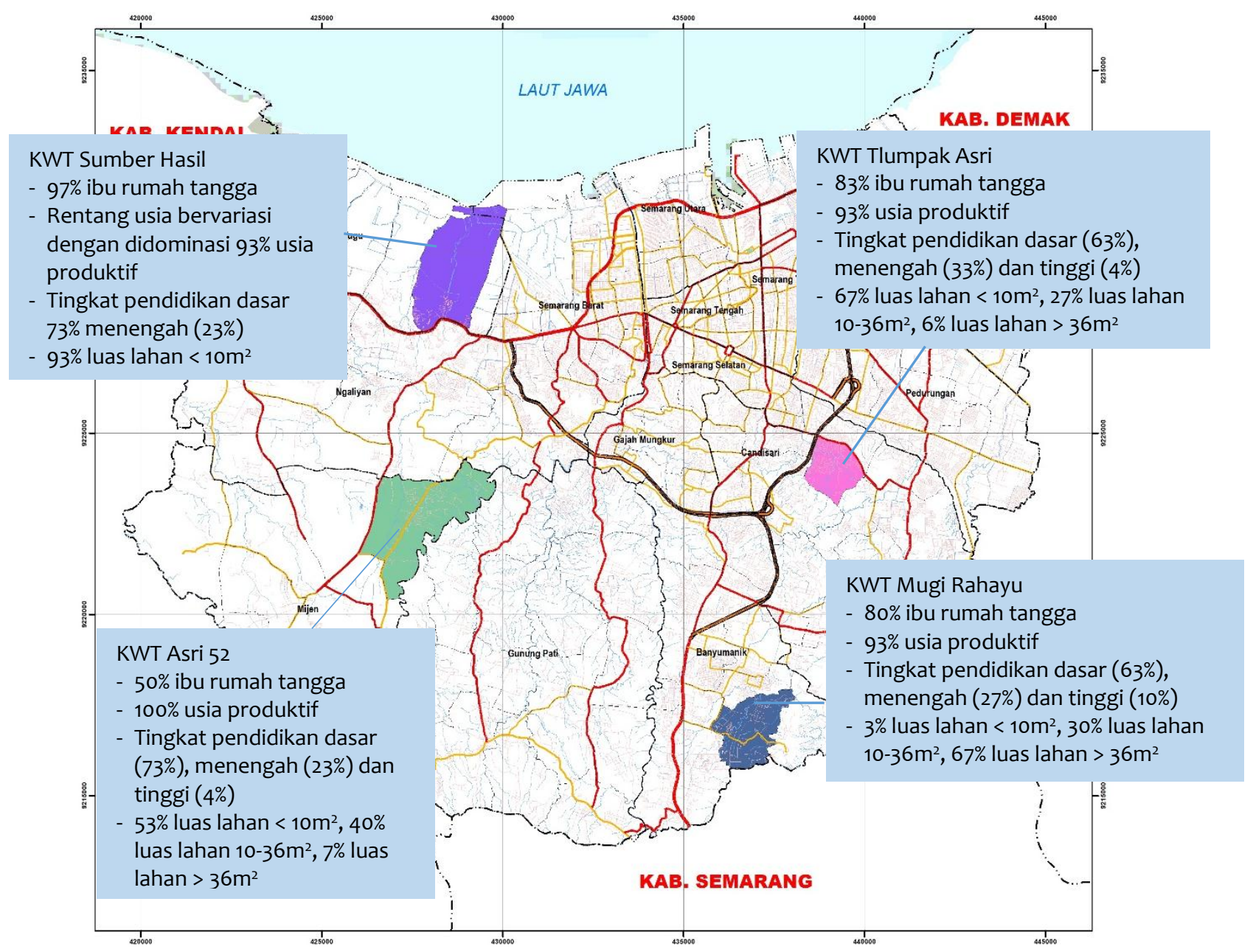

Sumber: Hasil Analisis, 2019

Gambar 2. Peta Persebaran Kondisi Kelompok Penerima Manfaat Program KRPL di Kota Semarang
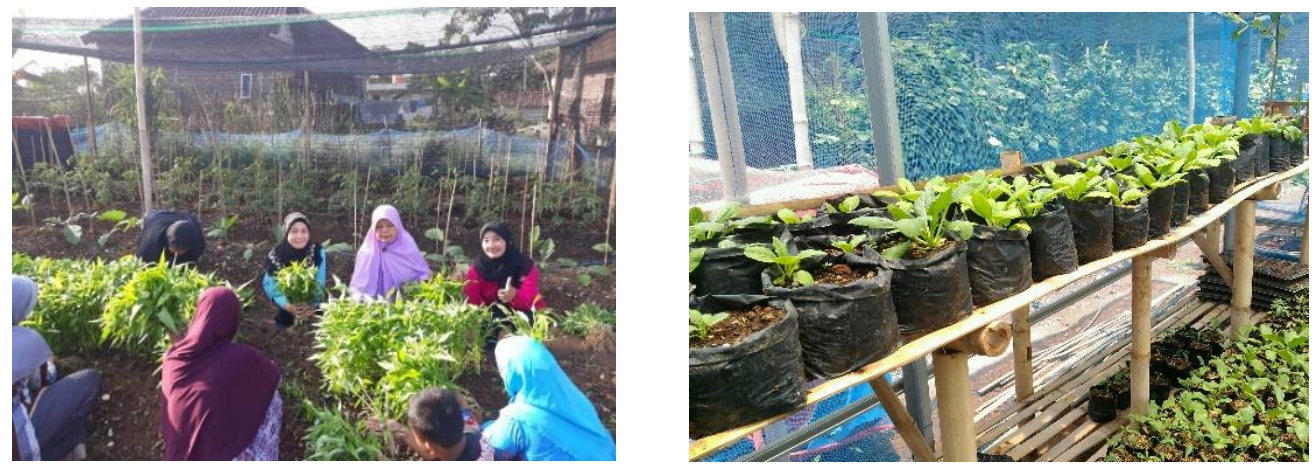

Sumber: Dokumentasi Lapangan, 2019

Gambar 3. Kondisi Demplot dan Kebun Bibit Kelompok 
Kebun bibit merupakan unit untuk memproduksi benih dan bibit untuk memenuhi kebutuhan bibit pekarangan anggota maupun untuk mensuplai kebutuhan bibit demplot kelompok. Secara umum kebun bibit betujuan agar anggota masyarakat dapat memenuhi kebutuhan benih dan bibit dari wilayah sendiri secara kontinyu. Untuk mendapatkan keuntungan ekonomi bagi kelompok, sebagian bibit hasil dari kebun bibit dapat diperjualbelikan. Oleh karena itu kebun bibit memegang peran penting untuk menjaga keberlangsungan kegiatan di kelompok. Ketika terjadi ketidakseimbangan antara produksi bibit dan kebutuhan bibit oleh kelompok, maka aspek keberlangsungan kegiatan di KRPL juga menjadi kendala tersendiri. Hal ini terjadi karena di lokasi penelitian kebun bibit tidak hanya dimanfaatkan oleh anggota kelompok, tetapi juga dimanfaatkan oleh masyarakat setempat. Hal ini ditunjukkan hasil penelitian yang menunjukkan bahwa 86\% anggota kelompok menyatakan bahwa kebun bibit dapat dimanfaatkan oleh masyarakat sekitar yang berniat mengembangkan pekarangan sebagai sumber pangan.

\subsection{Kontribusi Program terhadap Perekonomian Keluarga}

Perkembangan kota biasanya berbanding lurus dengan perkembangan ekonomi yang semakin kompleks, seperti halnya perkembangan fisik kota yang semakin meluas. Pada negara berkembang, sebagian besar penduduk menghabiskan setengah dari penghasilan untuk pangan. Demikian halnya di Indonesia, proporsi pengeluaran penduduk per bulan lebih besar untuk pangan dibanding bukan pangan. Pengeluaran untuk pangan rata-rata pada tahun 2017 mencapai 50,94 persen dari total pengeluaran penduduk setiap bulannya, sedangkan untuk kawasan perkotaan rata-rata menghabiskan 46,70 persen dari total pengeluaran (BPS, 2017). Hal inimenyebabkan orang miskin sangat rentan terhadap fluktuasi harga pangan yang mendadak yang dapat mendorong orang ke dalam kemiskinan dan/atau menghambat usaha pengentasan kemiskinan (Cranfield et al., 2007; Ivanic and Martin, 2008). Selain itu, berbagai perubahan berpengaruh cukup besar dalam menambahkan tekanan pada sistem pangan global, seperti perubahan iklim, degradasi tanah, hama, krisis ekonomi dan politik, dan pertumbuhan penduduk (Rockström et al., 2009; Godfray et al., 2010; Pretty et al., 2010).

Pada negara berkembang, banyak lapangan kerja baru yang dibutuhkan bagi tenaga kerja tidak terlatih maupun berpendidikan rendah, baik bagi para migran maupun penduduk asli perkotaan. Dengan peningkatan tenaga kerja berkisar 2-3\% tiap tahun di Afrika, Asia Timur dan Asia Tenggara maka ribuan lapangan kerja baru harus diciptakan tiap tahun di wilayah tersebut (Bakker et al., 2000). Di sisi lainnya, penduduk perkotaan menghadapi berbagai tantangan kepadatan, iklim, ketersediaan sumberdaya, budaya dan politik, sehingga banyak rumah tangga perkotaan menghadapi keterbatasan untuk mengakses kebutuhan, termasuk kebutuhan pangan. Hal tersebut menjadi salah satu hal yang mendasari perlunya menciptakan aktivitas ekonomi baru di kota, salah satunya melalui aktivitas pertanian perkotaan. Aktivitas pertanan perkotaan dapat menciptakan aktivitas ekonomi baru sekaligus membuka peluang kerja (Dieleman, 2017).

Aktivitas pertanian perkotaan muncul karena tingginya persaingan untuk bekerja pada sektor jasa perkotaan. Pada akhirnya penduduk perkotaan melakukan aktivitas pertanian di kawasan kota tempat tinggal mereka dengan memanfaatkan lahan kosong yang ada, lahan marginal maupun sarana lain yang bisa dimanfaatkan untuk pertanian perkotaan (Zhang et al., 2018). Beberapa alasan yang mendasari keterlibatan penduduk perkotaan diantaranya untuk pemenuhan kebutuhan sendiri, menghasilkan pendapatan, krisis ekonomi, tingginya harga pangan, diversifikasi pendapatan, peluang kerja, adanya konflik dan buruknya iklim (Bakker et al., 2000).

Berdasarkan data pengeluaran penduduk Kota Semarang tahun 2015 untuk pangan Rp.437.496,00 atau 34\% dari total pengeluaran penduduk yang lebih rendah daripada pengeluaran rata-rata untuk non pangan penduduk sebesar Rp.860.399,00 (67\% dari total pengeluaran penduduk Kota Semarang). Pengeluaran untuk sayur menempati 5,93\% dari total pengeluaran pangan penduduk dan buah menempati 7,21\%. Pangsa pengeluaran pangan penduduk berkorelasi negatif dengan kondisi ketahanan pangan karena 
tingginya pengeluaran pangan penduduk mengurangi ketahanan pangan penduduk (BPS, 2017). Komposisi pengeluaran pangan penduduk Kota Semarang mencerminkan ciri masyarakat perkotaan yang cenderung menyukai hal-hal yang bersifat praktis, termasuk pola pemenuhan pangannya yang lebih memilih membeli makanan jadi. Sementara itu, untuk pengeluaran untuk sayur dan buah lebih rendah bukan berarti menunjukkan pemenuhannya sudah dipenuhi secara mandiri, melainkan lebih menunjukkan konsumsi sayur dan buah kurang menjadi prioritas di keluarga.

Program KRPL hadir selain diharapkan mampu meningkatkan konsumsi pangan beragam bergisi seimbang, juga diharapkan memberikan kontribusi bagi perekonomian di keluarga. Berdasarkan hasil survei, program KRPL di Kota Semarang dijalankan lebih sebagai kegiatan sambilan dan hobi. Dari keseluruhan responden, belum ada responden yang menganggap kegiatan KRPL dapat membuka peluang pekerjaan yang mendatangkan margin keuntungan besar secara ekonomi. Responden yang menganggap KRPL sebagai aktivitas sambilan di sela-sela kegiatan kesehariannya sebanyak 79 responden (66\%) dan 41 responden sisanya (34\%) menganggap keikutsertaan dalam KRPL lebih sebagai hobi karena kesenangan terhadap tanaman dan gaya hidup sehat. Hal tersebut mengindikasikan, sektor pertanian perkotaan di Kota Semarang masih belum dipandang oleh masyarakat sebagai sektor yang menjanjikan. Program KRPL yang sejatinya dimaksudkan sebagai pemicu untuk menggerakkan kemandirian kelompok dalam pemenuhan pangan dan gizi sekaligus meningkatkan kesejateraan keluarga belum dapat dioptimalkan keberadaannya.

Hasil pemanfaatan pekarangan di Kota Semarang sebagian besar untuk dikonsumsi sendiri seeprti disajikan pada Tabel 1. Sebanyak 102 responden (85\%) menyatakan bahwa hasil pemanfaatan pekarangan anggota dikonsumsi sendiri untuk meningkatkan konsumsi pangan bergizi di keluarga untuk mengurangi biaya dapur. Sementara sebagian kecil lainnya sebanyak 18 responden (15\%) menyatakan bahwa hasil pemanfaatan pekarangan selain untuk konsumsi sendiri juga sudah mulai dijual ketika panen. Adapun sebaran

Tabel 1. Distribusi Pemanfaatan Hasil Pekarangan Anggota Menurut Kelompok Penerima Manfaat

\begin{tabular}{cccccc}
\hline Pemanfaatan Hasil Pekarangan Anggota & $\begin{array}{c}\text { KWT } \\
\text { Tlumpak Asri }\end{array}$ & $\begin{array}{c}\text { KWT } \\
\text { Mugi Rahayu }\end{array}$ & $\begin{array}{c}\text { KWT } \\
\text { Sumber Hasil }\end{array}$ & $\begin{array}{c}\text { KWT } \\
\text { ASRI 52 }\end{array}$ & Jumlah \\
\hline Dikonsumsi sendiri dan dijual & 6 & 2 & 2 & 8 & 29 \\
Dikonsumsi sendiri & 24 & 28 & 28 & 22 & 151 \\
Total & $\mathbf{3 0}$ & $\mathbf{3 0}$ & $\mathbf{3 0}$ & $\mathbf{3 0}$ & $\mathbf{1 2 0}$ \\
\hline
\end{tabular}

Sumber: Hasil Analisis, 2019

Mekanisme penjualan dari pekarangan pribadi sebagian dijual secara mandiri dan sebagian lainnya dijual secara kolektif bersamaan ketika panen di demplot kelompok. Sementara untuk hasil panen dari demplot kelompok, hasilnya dijual kepada anggota kelompok dan masyarakat sekitar, dan hasil penjualan akan dimasukkan ke dalam kas kelompok. Dari hasil wawancara, hasil demplot ketika panen mampu memberikan pemasukan uang kas kelompok hampir dua juta rupiah untuk beberapa komoditas yang diusahakan.

Berdasarkan hasil survei, sebagian besar anggota kelompok penerima manfaat ( $72 \%$ responden) memandang kegiatan pemanfaatan pekarangan dapat menghemat uang belanja seperti ditampilkan pada Gambar 3. Sebanyak 17\% responden menyatakan bahwa kegiatan KRPL mampu menghemat uang belanja dan menambah penghasilan keluarga. Namun ada juga responden sebanyak 11\% yang menganggap bahwa kegiatan KRPL tidak berpengaruh terhadap penghasilan keluarga.

Responden yang menyatakan tidak berkontribusi sebagian besar merupakan anggota kelompok penerima manfaat yang sudah tidak lagi mengusahakan pekarangan untuk kegiatan KRPL. Kondisi ini biasanya karena faktor perilaku, seperti cepat bosan dan semangat yang sudah menurun untuk meneruskan kegiatan KRPL secara mandiri. Selain itu juga dimungkinkan karena responden menilai bahwa program berkontribusi terhadap perekonomian jika mampu menghasilkan margin keuntungan yang cukup bagi penghasilan keluarga. Pengembangan komoditas yang belum berorientasi pasar juga dimungkinkan sebagai 
penyebabnya. Manfaat ekonomi belum dapat terwujud karena kurangnya akses pasar untuk penjualan produk akibat panen yang berlebih. Kurang tersedianya teknologi panen dan pasca panen membuat hasil panen kurang memiliki nilai tambah dan memiliki umur produk yang singkat karena ciri khas produk segar adalah produk yang cepat rusak (Ashari et al., 2012).

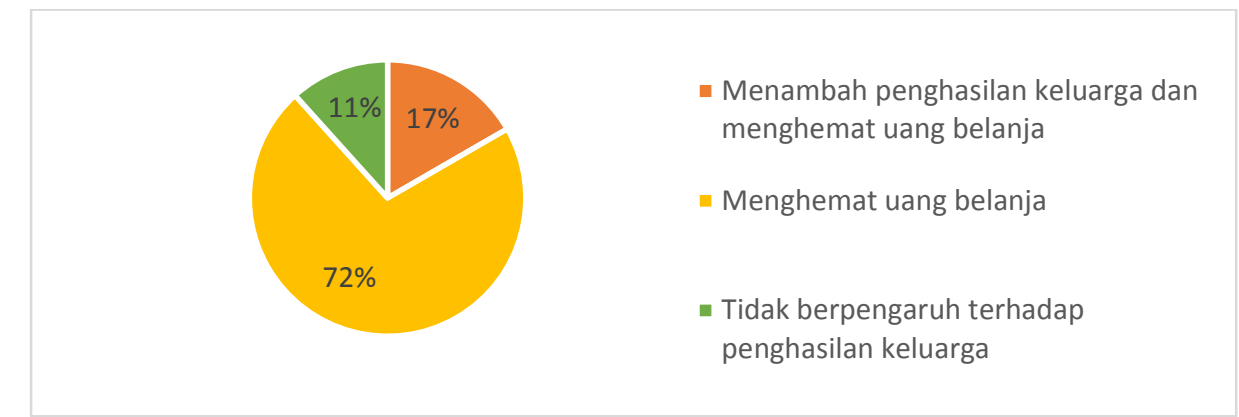

Sumber: Hasil Analisis, 2019

Gambar 3. Peran KRPL Terhadap Penghasilan Keluarga Penerima Manfaat

Sementara itu, sebagian besar anggota kelompok penerima manfaat memandang kegiatan pemanfaatan pekarangan dapat menghemat uang belanja. Sejumlah pengeluaran yang dapat dihemat akan berbeda beda tiap luasan pekarangan yang dimanfaatkan. Perbedaan jumlah pengeluaran yang dapat dihemat bukan hanya berdasarkan luasan namun juga berdasarkan cara keluarga tersebut dalam mengkonsumsi. Potensi pengeluaran yang dapat dihemat oleh keluarga bisa mencapai Rp 30.000-Rp 150.000. Pada luasan sempit pengeluaran yang dapat dihemat kurang lebih $\mathrm{Rp} 30.000$. Hal ini diasumsikan dengan pengeluaran perhari untuk membeli sayur mayur Rp 1000. Sementara untuk pekarangan yang luas diasumsikan dengan pengeluaran setiap hari Rp 5.000 untuk membeli sayuran, toga, buah atau ikan dapat menghemat Rp 150.000 per bulan. Semakin luas pekarangan, komoditas yang diusahakan semakin beragam, sehingga penghematan berpeluang lebih besar. Hal ini sesuai dengan hasil wawancara, bahwa pengeluaran yang dapat dihemat dapat berkisar Rp. 50.000 - Rp.100.000 setiap bulan.

Kondisi tersebut menunjukkan bahwa penerapan KRPL memberikan kontribusi positif bagi perekonomian, khususnya keluarga. Hasil penelitian menunjukkan bahwa program bermanfaat bagi penghematan pengeluaran domestik untuk pangan dan peningkatan pendapatan, meningkatnya kas dan aset kelompok sasaran program melalui penjualan bibit dan tanaman maupun hasil panen komoditas yang diusahakan oleh kelompok dan anggota. Dalam hal ini, faktor keberlanjutan program merupakan hal yang perlu menjadi perhatian. Manfaat ekonomi kurang bisa dirasakan dalam waktu singkat, oleh karenanya perlu sentuhan ekonomi dalam desain programnya. Kelompok penerima manfaat perlu dipaksa untuk mandiri setelah program usai, yang salah satunya adalah dengan memberikan keterampilan kepada anggota kelompok untuk bisa mengembangkan usaha dari hasil komoditas yang diusahakan oleh kelompok, melalui mekanisme pemasaran, penanganan pasca panen dan pengenalan pada jaringan mitra.

Walaupun saat ini KRPL di Kota Semarang belum signifikan dalam meningkatkan kondisi perekonomian kota melalui peningkatan PDRB namun sektor ini dianggap tetap memiliki peran dalam perekonomian lokal kawasan. Jika aktivitas ini dilakukan secara serius dan ditubuhkan dalam skala yang lebih luas, maka dapat sekaligus sebagai alternatif mengatasi kemiskinan kota sekaligus menciptakan aktivitas ekonomi baru, membuka peluang kerja dan berpotensi membentuk guna lahan kota yang lebih efektif dengan memanfaatkan lahan pekarangan, lahan kosong, maupun lahan marginal yang ada (Zhang et al., 2018; Dieleman, 2017). 


\section{KESIMPULAN}

Implementasi program KRPL sebagai salah satu bentuk aktivitas pertanian perkotaan dapat dikatakan masih belum sempurna bila dibandingkan dengan negara maju yang telah menerapkan aktivitas pertanian perkotaan. Hal ini sesuai dengan pendapat Badami dan Ramankutty (2015) yang menyatakan bahwa pertanian pertanian perkotaan lebih berhasil diterapkan di negara maju. Walaupun memiliki keterbatasan luas lahan dan populasi penduduk relatif kecil, segala sumber daya perkotaan dapat dikelola untuk keberhasilan aktivitas pertanian perkotaan. Kualitas penduduk yang baik dengan disertai penerapan teknologi pada setiap rantai dari hulu hingga hilir dengan dipayungi oleh komitmen yang kuat dari Pemerintah terbukti mampu memberikan hasil yang jauh lebih optimal dibanding dari negara berkembang yang memiliki ketersediaan lahan lebih besar dan populasi penduduk yang jauh lebih tinggi.

Walaupun tingkat keberhasilan aktivitas pertanian perkotaan masih cukup tertinggal dibanding dengan di negara maju, namun impelementasi program KRPL di Kota Semarang tetap perlu dipandang sebagai langkah yang positif. Program KRPL tidak hanya berfokus pada tujuan mewujudkan ketahanan pangan, melainkan juga mengandung pesan pemberdayaan untuk membangun aktivitas ekonomi produktif yang jika diintegrasikan dengan program lintas sektor yang bersifat dari hulu (budidaya produksi) sampai hilir (tindak lanjut pengolahan dan pemasaran hasil produksi) maka dalam jangka panjang berpotensi sebagai bagian dari upaya pengentasan kemiskinan dan peningkatan kualitas sumber daya manusia melalui peningkatan kualitas pangan dan gizi.

Implementasi program KRPL di Kota Semarang dinilai secara nyata memberikan kontribusi positif terutama dirasakan bagi kelompok penerima manfaat. Dalam bidang ekonomi, walaupun belum dapat tergarap dengan optimal, setidaknya program ini mampu memberikan kontribusi bagi pengeluaran domestik untuk pangan dan peningkatan kesejahteraan. Potensi ini perlu terus ditumbuhkan dan didukung melalui pendekatan yang bersifat komprehensif, terutama untuk menjaga keberlangsungannya dan memperluas skalanya.

\section{PERNYATAAN RESMI}

Terima kasih penulis sampaikan kepada Pusat Pendidikan Pertanian, Badan Penyuluhan dan Pengembangan Sumber Daya Manusia Pertanian Kementerian Pertanian dan Badan Ketahanan Pangan Kementerian Pertanian atas dukungan dalam penyelesaian penelitian ini.

\section{REFERENSI}

Akter, S. et al. 2017. "Women's Empowerment and Gender Equity in Agriculture: A Different Perspective from Southeast Asia." Food Policy. Vol.69. pp. 270-279.

Badami, M. G. and Ramankutty, N. 2015. "Urban Agriculture and Food Security: A Critique Based on an Assessment of Urban Land Constraints." Global Food Security. Vol.4. pp. 8-15.Bakker, N. et al. (2000) Growing Cities, Growing Food: Urban Agriculture on the Policy Agenda. Fedaving: DSE. doi: Cities Feeding People Series Report 31.

Caballero-Serrano, V. et al. 2016. "Plant Diversity and Ecosystem Services in Amazonian Homegardens of Ecuador." Agriculture, Ecosystems and Environment. Vol.225. pp. 116-125.

Creswell, J. W. 2009. Research Design: Qualitative, Quantitative and Mixed Approaches. Third Edition. California: Sage Publication.

Dieleman, H. 2017. "Urban Agriculture in Mexico City; Balancing Between Ecological, Economic, Social and Symbolic Value." Journal of Cleaner Production. Vol.163. pp. S156-S163.

Ferdous, Z. et al. 2016. "Development of Home Garden Model for Year Round Production and Consumption for Improving Resource-poor Household Food Security in Bangladesh." NJAS - Wageningen Journal of Life Sciences. Vol.78. pp. 103-110.

He, C. et al. 2017. "Urban Expansion Brought Stress to Food Security in China: Evidence from Decreased Cropland Net Primary Productivity." Science of the Total Environment. Vol.576(19). pp. 660-670.

Kamiyama, C. et al. 2016. "Non-market Food Provisioning Services via Homegardens and Communal Sharing in Satoyama Socio-ecological Production Landscapes on Japan's Noto Peninsula." Ecosystem Services. Vol.17. pp. 
$185-196$.

Kumar, B. M. 2011. "Species Richness and Aboveground Carbon Stocks in the Homegardens of Central Kerala, India." Agriculture, Ecosystems and Environment. Vol.140(3-4). pp. 430-440.

Listya, D. et al. 2014. "Kajian Peran Pertanian Perkotaan Dalam Pembangunan Perkotaan Berkelanjutan (Studi Kasus: Pertanian Tanaman Obat Keluarga di Kelurahan Slipi, Jakarta Barat)." Forum Ilmiah. Vol.11(3). pp.323-333.

Lwasa, S. et al. 2014. "Urban and Peri-urban Agriculture and Forestry: Transcending Poverty Alleviation to Climate Change Mitigation and Adaptation." Urban Climate. Vol.7. pp. 92-106.

Maye, D. 2019. "Smart Food City: Conceptual Relations Between Smart City Planning, Urban Food Systems and Innovation Theory." City, Culture and Society. Vol.16. pp. 18-24.

Mohri, H. et al. 2013. "Assessment of Ecosystem Services in Homegarden Systems in Indonesia, Sri Lanka, and Vietnam." Ecosystem Services.Vol.5, pp. 124-136.

Mulyani, A. et al. 2015. "Analisis Konversi Lahan Sawah : Penggunaan Data Spasial Resolusi Tinggi Memperlihatkan Laju Konversi yang Mengkhawatirkan." Jurnal Tanah dan Iklim. Vol.40(2). pp. 121-133.

Nagoda, S. and Nightingale, A. J. 2017. "Participation and Power in Climate Change Adaptation Policies: Vulnerability in Food Security Programs in Nepal." World Development. Vol.100, pp. 85-93.

Niñez, V. 1987. "Household Gardens: Theorical and Policy considerations."Agricultural Systems, Vol.23.pp. 167-186.

Pengeluaran untuk Konsumsi Penduduk Indonesia 2017. BPS. 2017

Purwantini, T. B., et al. 2012. "Program Kawasan Rumah Pangan Lestari (KRPL) di Kabupaten Pacitan: Analisis Dampak dan Antisipasi ke Depan." Analisis Kebijakan Pertanian, Vol.10(3). pp. 239-256.

Putri, N. P. A., et al. 2015. "Evaluasi Keberlanjutan Kawasan Rumah Pangan Lestari (KRPL) di Desa Girimoyo, Kecamatan Karangploso, Malang." Jurnal Proteksi Tanaman, Vol.3(4). pp. 278-285.

Sirnawati, E., et al. 2015. "Faktor-faktor yang Mempengaruhi Keberhasilan Kawasan Rumah Pangan Lestari di Pulau Sumatera." Jurnal Pengkajian dan Pengembangan Teknologi Pertanian. Vol.18. pp. 11-28.

Whitney, C. W. et al. 2017. "Homegardens and the future of food and nutrition security in southwest Uganda." Agricultural Systems. Vol.154. pp. 133-144.

Zhang, J. et al. 2018. "Improving Food Security in China by Taking Advantage of Marginal and Degraded Lands." Journal of Cleaner Production. Vol.171, pp. 1020-1030. 